\title{
HYDRATION CHARACTERISTICS OF BLENDED CEMENT CONTAINING METAKAOLIN.
}

\author{
Hagrass, A. A."; Ibrahim, S. S. ; El-Hosiny, F. I.*; Youssef, S. I. ${ }^{*}$ and Moharam, M. R. ${ }^{\S}$ \\ * Tabbin Institute for Metallurgical Studies, Helwan, Cairo, Egypt. \\ ${ }^{\dagger}$ Central Metallurgical R\&D Institute, Helwan, Cairo, Egypt. \\ ${ }^{*}$ Faculty of Science, Ain Shams University, Cairo, Egypt. \\ ${ }^{\S}$ Faculty of Engineering, Al-Azhar University, Cairo, Egypt.
}

\begin{abstract}
Meta-kaolin as a pozzolanic active material was prepared by firing kaolin ore at different temperatures ranged from $500-1000^{\circ} \mathrm{C}$ for different soaking times from $1-5$ hours. Optimization of the preparation study was carried out. The optimum conditions were shown to be at $750^{\circ} \mathrm{C}$ for 5 hours. Mechanical and physico-chemical characterization of blended cement pastes made by partial replacement of Portland cement (PC) with $0,5,10$ and 15 wt. \% of metakaolin were studied. The pastes were hydrated for various time intervals of $1,3,7,14$ and 28 days. At each time interval, the hydrated pastes specimens were tested for compressive strengths, hydration kinetics, differential scanning calorimetry, XRD analysis and scanning electron microscopy. Blended pastes made of $90 \%$ OPC $+10 \%$ MK showed the highest compressive strength values at all hydration ages. DSC thermograms and XRD diffractograms results showed the formation of nearly amorphous calcium silicate hydrates (mainly as CSH. I \& II), calcium sulphoaluminate hydrates (ettringite and monosulphate hydrates), calcium aluminate hydrates, calcium hydroxide $(\mathrm{CH})$ and $\mathrm{CaCO}_{3}$. Scanning electron microscopy micrographs indicated the formation of denser microstructure for the hardened OPCMK pastes as compared to neat OPC pastes after 28 days.
\end{abstract}

Keywords: Blended Cement, Ordinary Portland Cement, Metakaolin, compressive strengths, hydration kinetics.

\section{INTRODUCTION}

Increased attention to the environmental impact of ordinary Portland cement (OPC) has prompted researchers to search for alternative clinkers with less construction materials [1]. Partial replacement of Portland cement by different pozzolanic materials such as metakaolin, fly ashes and blast furnace slag, represents a common route to reduce $\mathrm{CO}_{2}$ emissions [2]. Metakaolin (MK) was used widely as a highly reactive pozzolanic material [3]. Its physical and chemical characteristics greatly depend on the starting raw kaolinite ore used and temperature of calcination [4]. The calcination temperature of kaolinite is usually fell in the range between $500-900^{\circ} \mathrm{C}$ depending on the crystallinity and purity of the raw kaolinite used [5-10]. At higher temperatures $\left(>900^{\circ} \mathrm{C}\right)$, the metakaolin undergoes further reactions to form crystalline compounds [11]. In the presence of water, metakaolin, goes into reaction with $\mathrm{CH}$ which is released in the hydration of cement and forms calcium alumina hydrate and alumina silicate hydrate crystal structured products (such as $\mathrm{C}_{2} \mathrm{ASH}_{8}$-stratlingite, $\mathrm{C}_{4} \mathrm{AH}_{13}$ and $\mathrm{C}_{3} \mathrm{ASH}_{6-}$ hydrogarnet) [12,13]. Rashad A. M. (2013) investigated in detail the performance of metakaolin as pozzolan and its effect on improvement of properties of concretes and 
mixtures [14]. Mahyuddin B. R. and Alonge O. R. (2016) studied the physical properties of metakaolin produced in the laboratory from purified Kaolin [15]. Ioannis P. et al. (2014) investigated the effect of replacement of cement or limestone powder by metakaolin, on the rheology and the mechanical characteristics of the concrete mixtures. It has been found that the compressive strength is significantly enhanced and a similarly increasing trend is observed for higher replacement levels, regardless of the replaced material [16]. The pozzolanic reactivity of metakaolin (MK), and the effects of MK on mechanical properties, pore structure and heat of hydration of mortars made by replacing the cement with $\mathrm{MK}$ at $0 \%, 6 \%, 10 \%$, and $14 \%$ by weight at a constant 0.17 $\mathrm{w} / \mathrm{b}$ ratio were studied [17]. Results concluded that with the consideration of mechanical properties and heat of hydration, $10 \% \mathrm{MK}$ content mortar is more favorable than the others. A study on the influence of nano-metakaolin (NMK) on physical, mechanical and microstructural properties of high volume vermiculite blended white Portland cement (WPC) was investigated [18].

Results revealed a significant enhancement in both compressive and flexural strength, and about 57 and 59\%, increase respectively were obtained at 10\% NMK replacement. The effect of up to 20 wt. \% substitutions of OPC by MK on the hydration characteristics of MK-blended cement pastes was investigated [11]. The results indicated that substitution of up to $20 \mathrm{wt}$. \% OPC by MK as pozzolanic materials resulted in an increase in the standard water of consistency, acceleration of the initial setting times, high compressive strength values at earlier ages and improvement of the mechanical and durability properties. The Pozzolanic and hydraulic activity of nanometakaolin were investigated [19]. The results indicated that the optimum firing temperature of metakaolin (MK) was $750^{\circ} \mathrm{C}$ for $2 \mathrm{hrs}$. The effect of inclusion of metakaolin on the hydration characteristics and microstructure of hardened OPC-MK pastes was studied [20]. The compressive strength results revealed that the inclusion of metakaolin into OPC improved the mechanical properties of $\mathrm{MK}-\mathrm{OPC}$ pastes during almost all ages of hydration, especially with the paste containing $10 \mathrm{wt}$ \% MK.

\section{Experimental Procedures}

Technological sample of the ordinary Portland cement CEM I 52.5R (OPC) was kindly provided by El Arish Cement Company, North Sinai, Egypt. Meanwhile, a representative kaolin ore sample was gathered from El-Teeh deposit, northeast of Abu Zenima locality, Sinai Peninsula, Egypt. Kaolin ore sample was subjected to size reduction and fine grinding using an attritor unit. The ground kaolin was subjected to series of hydro-cyclones to reject the fine silica $>10$ microns. The refined kaolin was then subjected to calcination study to optimize the formation of metakaolin material. Calcination temperatures between 500 to $1000^{\circ} \mathrm{C}$ and firing soaking periods between 1 $\mathrm{hr}$ to $5 \mathrm{hrs}$ were the main studied factors that controlling the metakaolin formation.

Differential thermal analysis (DTA) study was carried out using "NETZSCH STA 409 C/CD" adapted to follow the calcinations process. Phase composition analysis was conducted using XRD diffractometer, model" Bruker axs, D8 Advance. Scanning electron microscope (SEM) model FEI Inspect S50 has been used to study the morphology and microstructure of the samples. Series of mixtures were prepared from OPC, blended with different amounts of metakaolin as shown in table 1. 
Table (1): Percentage composition of metakaolin cement blends.

\begin{tabular}{|c|c|c|}
\hline Mix & OPC & MK \\
\hline MK0 & 100 & 0 \\
\hline MK5 & 95 & 5 \\
\hline MK10 & 90 & 10 \\
\hline MK15 & 85 & 15 \\
\hline
\end{tabular}

Each dry mixture was mechanically stirred for $3 \mathrm{hrs}$ in porcelain mixer to attain complete homogeneity, and then kept in airtight containers for further investigation. The water requirements of the cementitious mixtures (Normal consistency) as well as initial and final setting times were measured by Vicat apparatus according to ASTM C 187,191 [11]. The mixing of OPC and blended cement dry mixtures was carried out with the required water of consistency. Each dry mixture was mixed with water for about 3 minutes. After mixing, the resulting pastes were molded into cubic specimens $(2.54 \mathrm{~cm} \times 2.54 \mathrm{~cm} \times 2.54 \mathrm{~cm})$ by using stainless steel cubic moulds. Immediately after molding, the moulds were cured at about $100 \%$ relative humidity at room temperature for the first 24 hours in order to attain the final setting of the specimens [19]. After 24 hrs, the hardened cement pastes were then removed from the moulds and cured under tap water for 28 days. The applied time intervals were 3, 7, 14 and 28 days of hydration. At each hydration time intervals, 3 cubes represent each hardened pastes are subjected to compressive strength test. The stopping of hydration process was performed on the crushed cubic specimens after the compressive strength determination. The stopping solution was composed of methyl alcohol and acetone (1:1 by volume) [21].

Finally, the powdered samples were dried at $80^{\circ} \mathrm{C}$ for three hours in $\mathrm{CO}_{2}$ - free atmosphere and maintained in a desiccator for further investigation. Kinetics of hydration process was studied from the determination of chemically-combined water contents $(\mathrm{CW}, \%)$ and free lime $(\mathrm{CaO}, \%)$ contents for the hardened specimens at different intervals time of hydration [19]. Some selected samples of OPC-MK cement pastes were directed to X-ray diffraction analysis. The thermal behavior of the hydrated specimens of different OPC-MK mixes was tested by differential scanning calorimetry (DSC) technique using DSC-50 instrument from Shimadza (Japan) at heating rate of $10^{\circ} \mathrm{C} / \mathrm{min}$.

\section{RESULTS AND DISCUSSIONS}

\subsection{Compressive Strength Measures and Hydration Kinetics of Neat OPC and OPC-MK Hardened Pastes.}

The results of compressive strength of neat and blended cement pastes containing 5, 10 and $15 \% \mathrm{MK}$ are represented in figure 1 . The partial substitution of OPC-MK after hydration for 1, 3, 7, 14 and 28 days showed improving in compressive strength values than the neat OPC paste especially at later hydration ages. This increase in the compressive strength values are mainly attributed to the pozzolanic reaction between the free calcium hydroxide $(\mathrm{CH})$, liberated from Portland cement hydration, with metakaolin (MK) to form excessive amounts of hydration products, mainly CSH gel as well as stabilization of CSH hydrates, which fill the voids and pores that leads to a reduction in the total porosity as well as an increase in the total contents of binding 
centers in the specimens, [22-23]. Beside, according to the data obtained in figure 1, it was found that, at each hydration age the compressive strength values increase with increasing of MK content in blended cement pastes up to $10 \mathrm{wt}$. \%. This was followed by a reduction in the compressive strength values at $15 \% \mathrm{MK}$. This is mainly due to the dilution of OPC content, which has more hydraulic properties than MK, [19]. Therefore, the maximum improvement in the compressive strength of the hardened cement pastes was found at $10 \% \mathrm{MK}$ as a partial substituent of OPC. However, the improvement in the compressive strength with different additions of MK may be explained as follows: when water is added to the OPC-MK mixture, lime concentration will be high as a result of initial hydration of OPC, the silica and alumina go into solution quickly and react to form hydration products (mainly calcium silicate hydrate) together with formation of hexagonal calcium aluminate hydrate (mainly as $\mathrm{C}_{4} \mathrm{AH}_{13}$ ) which are precipitated as soon as saturation is approached. For hardened paste MK15 (85\% OPC $+15 \% \mathrm{MK}$ ), results of compressive strength showed a relatively lowering values compared to that in case of MK5 and MK10. Meanwhile, these low values were relatively higher than that of neat OPC paste (MK0) during all ages of hydration, figure 1. It was reported that the slight decrease in the strength values of the hardened pastes made of mixes having higher percentages of MK (such as $15 \% \mathrm{MK}$ ) may be attributed to the presence of residual (unreacted) amounts of MK which act as filler in the hardened OPC-MK pastes [24].

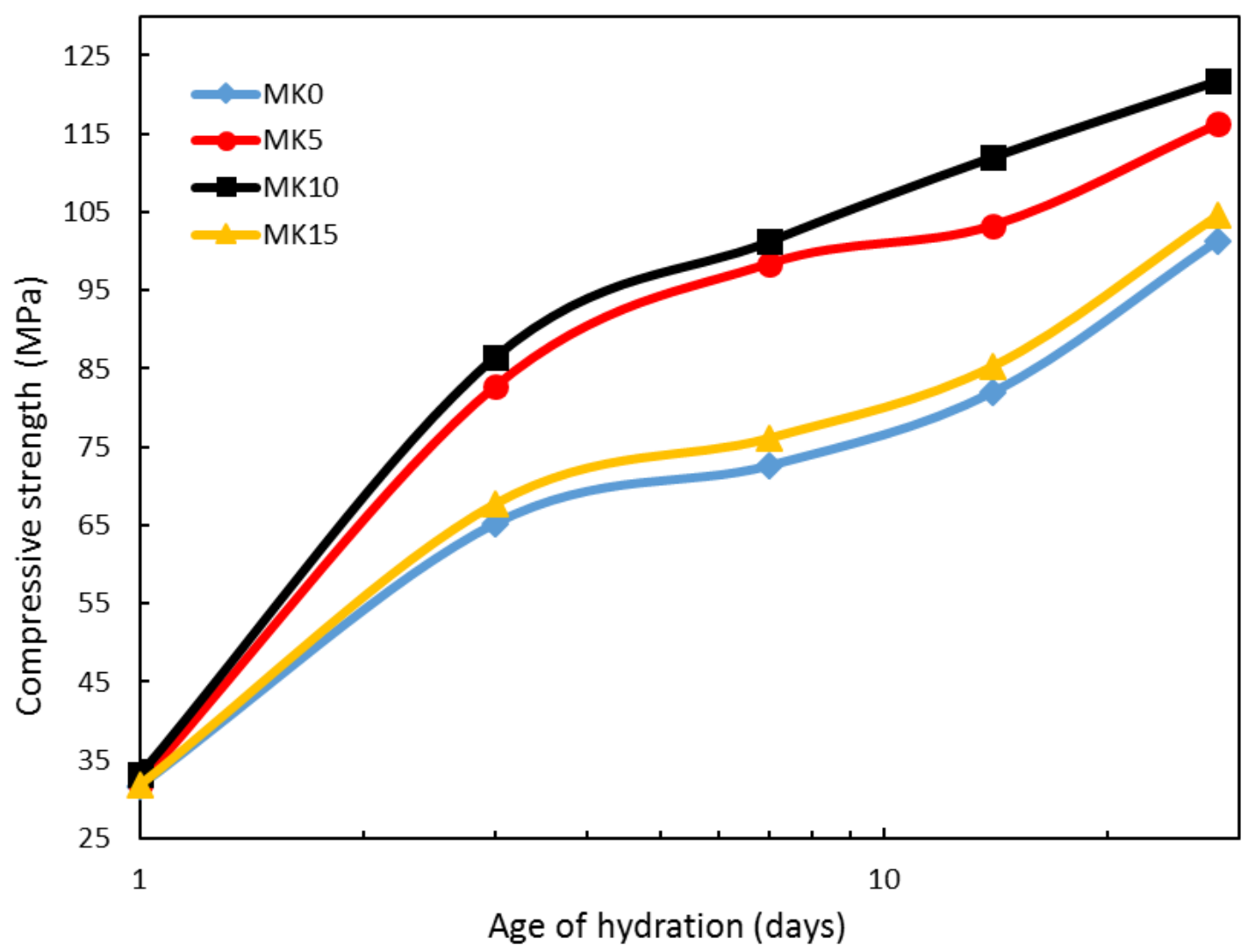

Fig. 1: Compressive strength (MPa) versus age of hydration for neat OPC and various OPC-MK hardened pastes. 
Figure 2 illustrates the results of chemically combined water content versus the ages of hydrations for the investigated pastes (MK0 - MK15). The results showed a fast hydration reaction takes place from the time of mixing up to 3 days of hydration, figure 2. This was followed by a considerable increase in $(\mathrm{Cw} \%)$ up to 7 days of hydration. However, that, the initially formed hydration products shield the cement grains leading to a slower rate of hydration reaction; this is followed by a gradual increase in the rate of hydration up to the final stages of hydration (28 days).

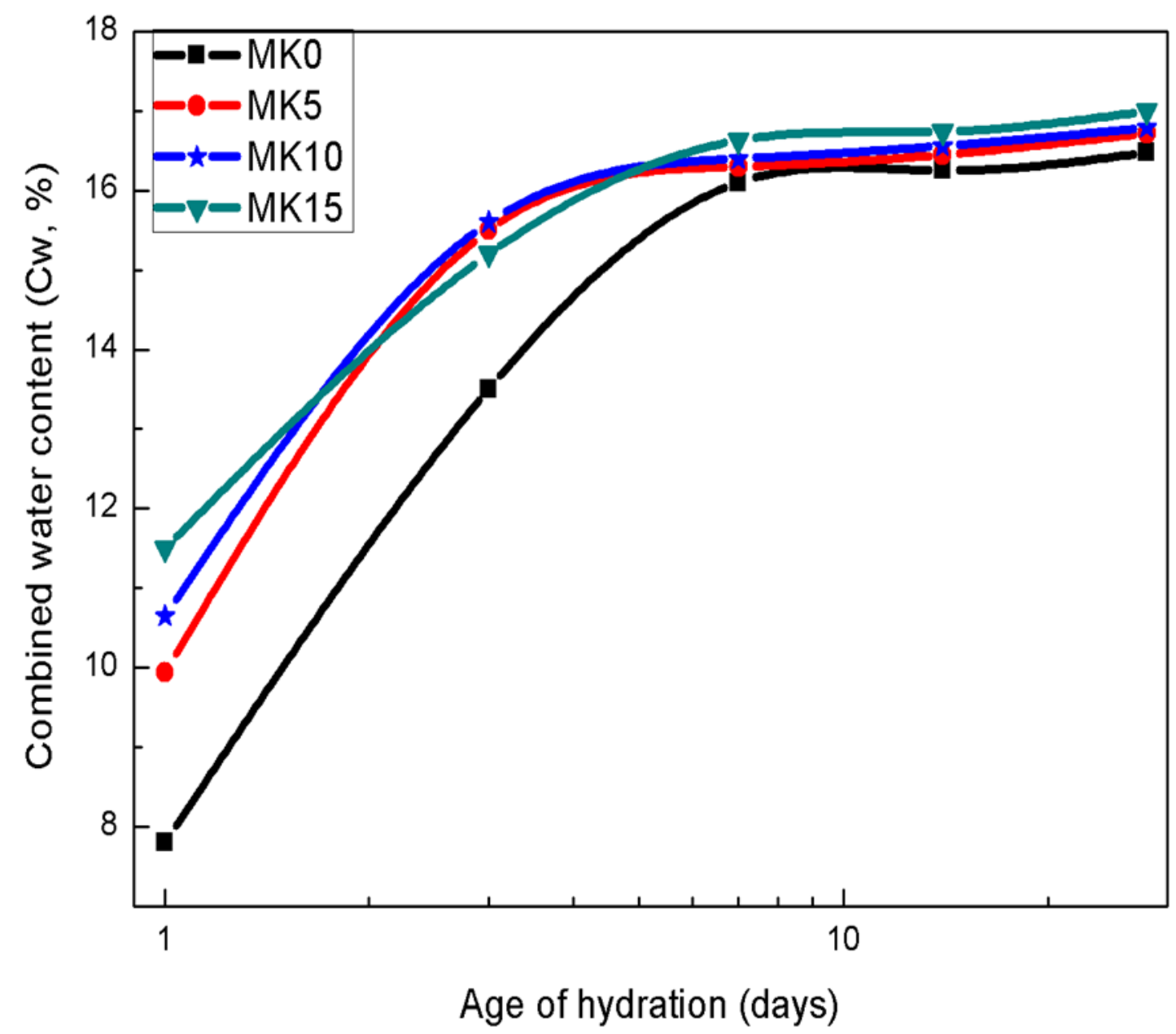

Fig. 2: Chemically combined water content versus age of hydration.

Figure 3 represents the results of the free lime contents $(\mathrm{CaO}, \%)$ versus age of hydration for the hardened cement specimens (MK0 - MK15). Results showed that the produced free lime content $(\mathrm{CH})$ increases gradually with increasing age of hydration up to 28 days. The observed free lime contents for all OPC-MK hardened pastes were a result of two opposite actions. The first action was the increase in the amount of free lime, which liberated from hydration of Portland cement, and the second action was the consumption of such liberated lime via its pozzolanic reaction with MK. Therefore, the results indicate that the free lime contents obtained after all admixed OPC-MK pastes were lower than those of the neat OPC paste. In addition, as the percentage of metakaolin replacement increased, the free lime content decreased because of the consumption of free lime by the pozzolanic reaction. Obviously, the pozzolanic cement 
paste having the highest MK content (MK15) has the lowest free lime contents at all ages of hydration; this is due to the remarked consumption of free lime by metakaolin because of the pozzolanic reaction. These results are in agreement with the results reported in earlier publications [22].

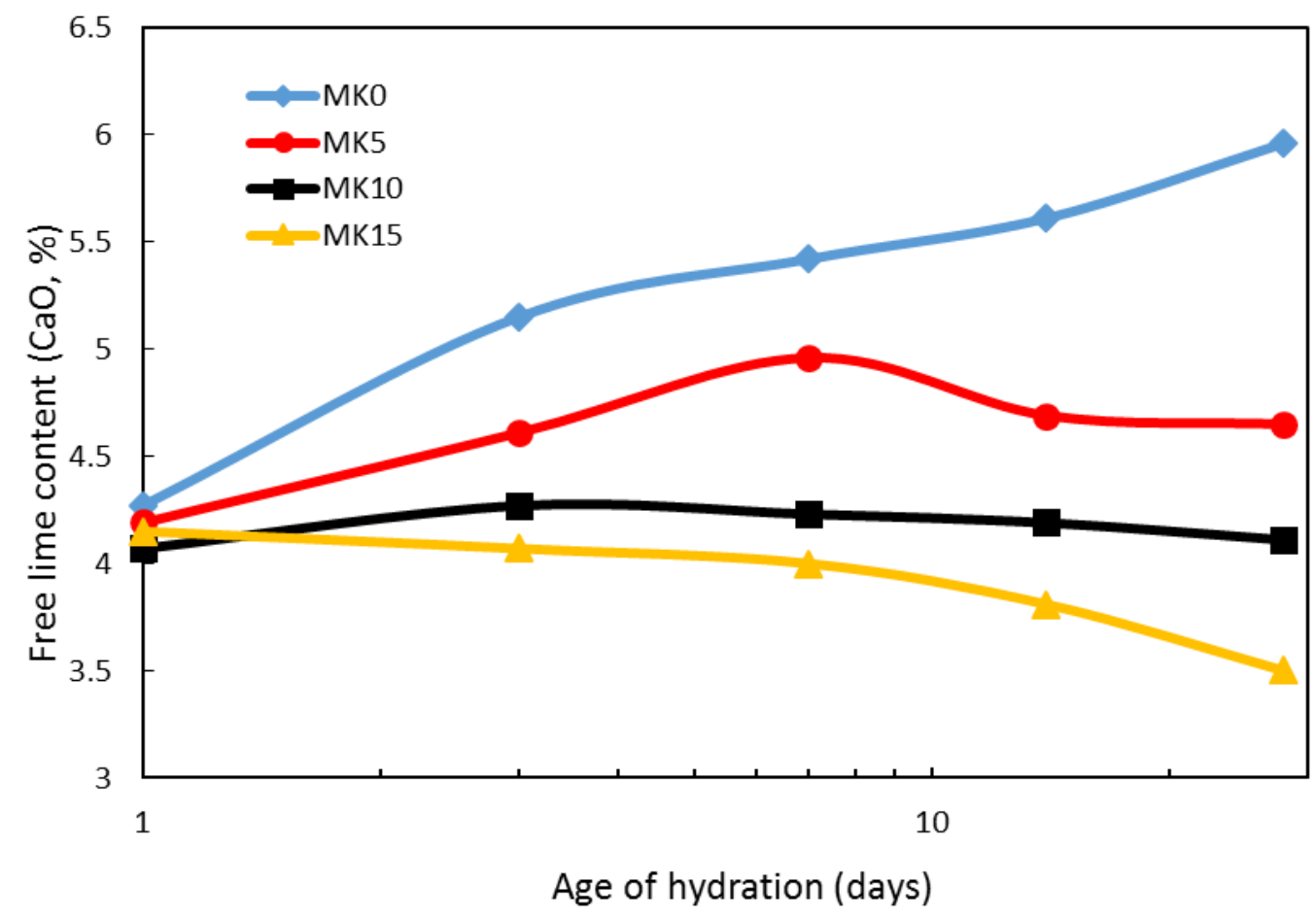

Fig. 3: Free lime content versus age of hydration for neat $\mathrm{OPC}$ and various OPCMK hardened pastes.

\subsection{Thermo-gravimetry (TG), Differential Scanning Calorimetry (DSC), and Differential Thermo-gravimetry (DTA) thermograms Analyses.}

Thermo-gravimetry (TG), Differential Scanning Calorimetry (DSC), and Differential Thermo-gravimetry (DTG) thermograms analyses of the hardened pastes made of neat OPC (MK0) and the blended pastes made of $90 \%$ OPC and 10\% metakaolin (MK10) after 1,14 and 28 days of hydration at room temperature are shown in figures 4.1a, $4.1 \mathrm{~b}, 4.1 \mathrm{c}$, and $4.2 \mathrm{a}, 4.2 \mathrm{~b}, 4.2 \mathrm{c}$, respectively. For the control hardened cement paste, MK0, showed three endothermic peaks between $60^{\circ} \mathrm{C}$ and $130^{\circ} \mathrm{C}$ are suggested to be due the evaporation of free water beside the dehydration of the interlayer calcium silicate hydrates $(\mathrm{CSH})$, calcium aluminate hydrates $(\mathrm{CAH})$ and calcium sulphoaluminate hydrates, figures $4.1 \mathrm{a}, 4.1 \mathrm{~b}$ and $4.1 \mathrm{c}$, [25]. The intensity of these endothermic peaks showed gradual increasing with the increase of the hydration time due to the excessive formation of larger amounts of $\mathrm{CSH}$ and/ or the latter crystallization of $\mathrm{CSH}$ with increasing age of the main hydration products of OPC. The gradual increase in the decomposition rate of calcium hydroxide $(\mathrm{CH})$ liberated from the hydration of OPC with increasing the aging time was appeared as a big endothermic peak at $410-450^{\circ} \mathrm{C}$ that represents the main weight loss, figures $4.1 \mathrm{a}, 4.1 \mathrm{~b}$ and $4.1 \mathrm{c}$. The endothermic reaction due to the decomposition of calcium carbonate was shown as endothermic peak located between $660^{\circ} \mathrm{C}$ and $720^{\circ} \mathrm{C}$, [26]. However, the decrease in the intensity of this endothermic peak with increasing the hydration age could be attributed 
to the reaction of $\mathrm{CO}_{2}$ with $\mathrm{CaCO}_{3}$ to form $\mathrm{Ca}\left(\mathrm{HCO}_{3}\right)_{2}$, figures $4.1 \mathrm{a}, 4.1 \mathrm{~b}$ and $4.1 \mathrm{c}$ and/ or the increase in the degree of crystallinity of $\mathrm{CaCO}_{3}$. This indication is accounted for the degree of carbonation of the hardened pastes. The hardened blended cement pastes showed the same endothermic peaks in their TG, DSC and DTG as in the neat cement pastes indicates the same hydration products are formed in the metakaolin- OPC blended pastes as in the neat OPC pastes. However, the endothermic peaks located between $90^{\circ} \mathrm{C}$ and $150^{\circ} \mathrm{C}$ is due to the decomposition of calcium silicate hydrates (CSH) which overlapped with calcium sulphoaluminate hydrates (ettringite and meno sulphate hydrates), figures $4.2 \mathrm{a}, 4.2 \mathrm{~b}$ and $4.2 \mathrm{c}$. The intensity of these endothermic peaks increases with the increase of hydration time due to the excessive formation of larger amounts of calcium silicate hydrates $(\mathrm{CSH})$, as well as the pozzolanic reaction between the liberation $\mathrm{CH}$ and $\mathrm{MK}$. The endothermic peak located at $400-440^{\circ} \mathrm{C}$ represents the major loss in weight due to the decomposition of calcium hydroxide (portlandite). The intensity of this endotherm peak decreases with increasing age of hydration, figures 4.2a, 4.2b and 4.2c. Beside, this endothermic peak shows lower intensity compared to that obtained in case of neat OPC. These results are explained in terms of the decrease in the amount of free calcium hydroxide due to its pozzolanic consumption with MK. The endotherm located at $640-710^{\circ} \mathrm{C}$ related to the decomposition of calcium carbonate with different degrees of crystallinity.

These endothermic peaks are accounted for the degree of carbonation of the hardened pastes.

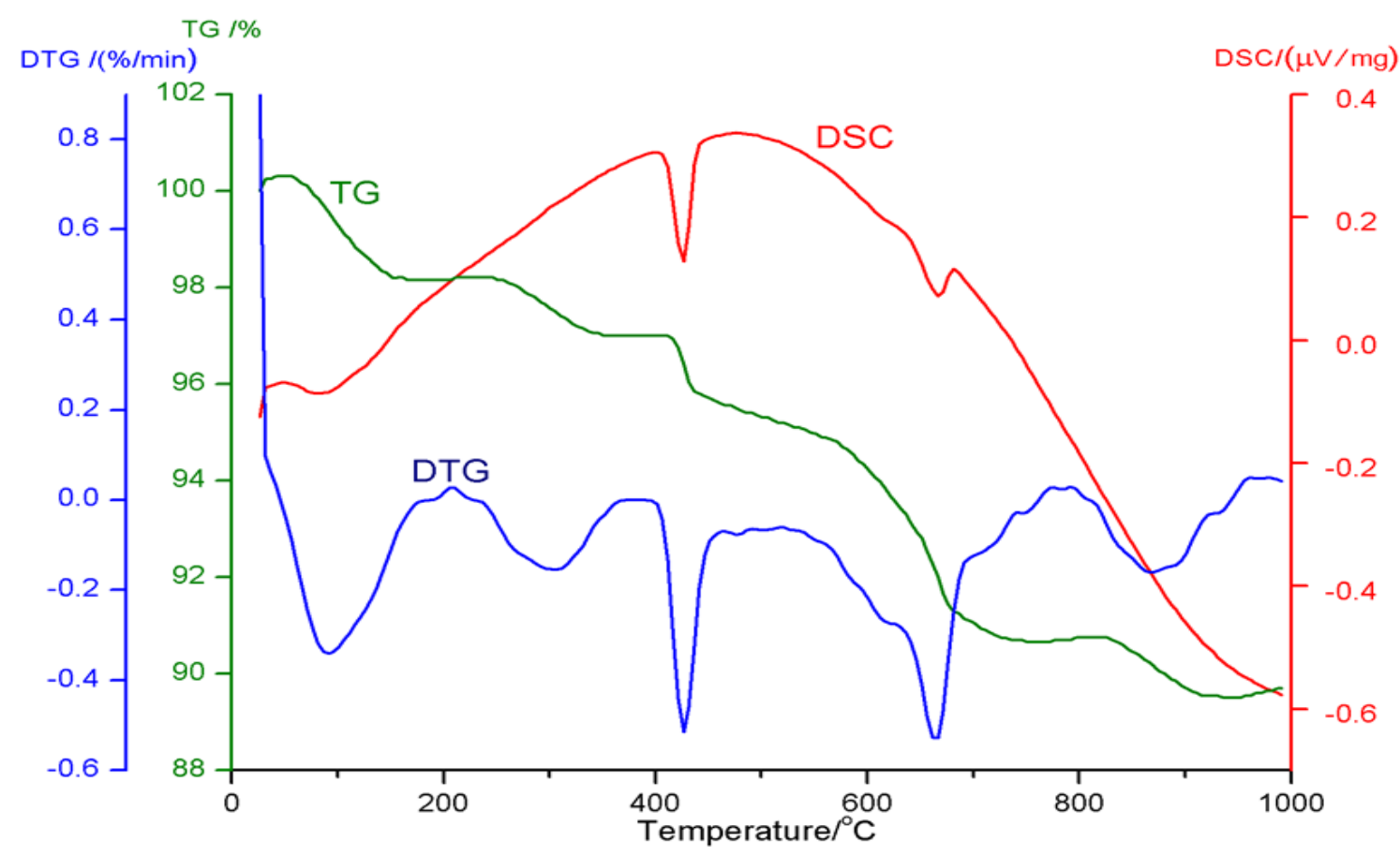

Fig. 4.1a: The TG, DSC and DTG thermograms of the hardened neat OPC after 1 day. 


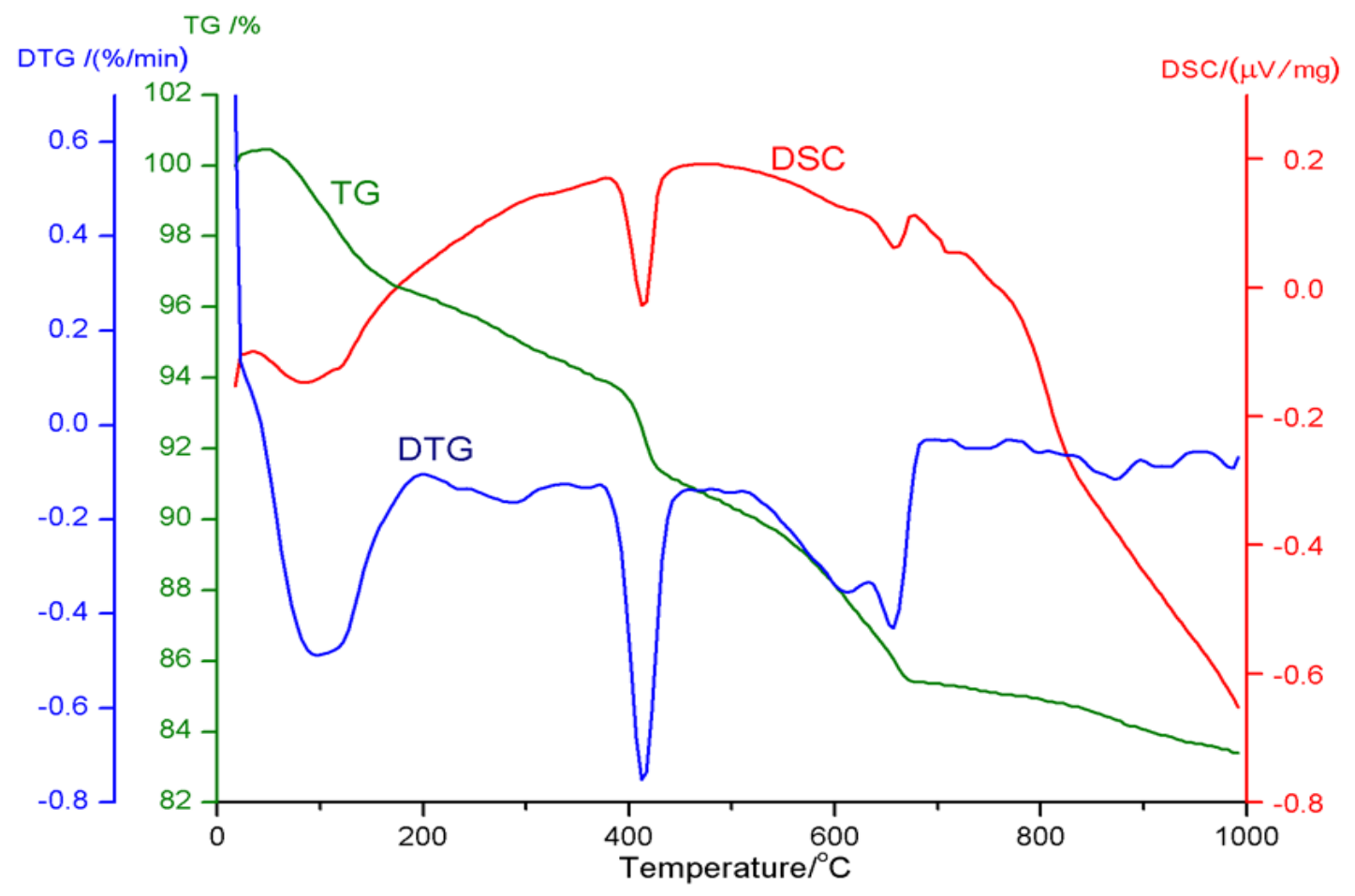

Fig. 4.1b: The TG, DSC and DTG thermograms of the hardened neat OPC after 14 days.

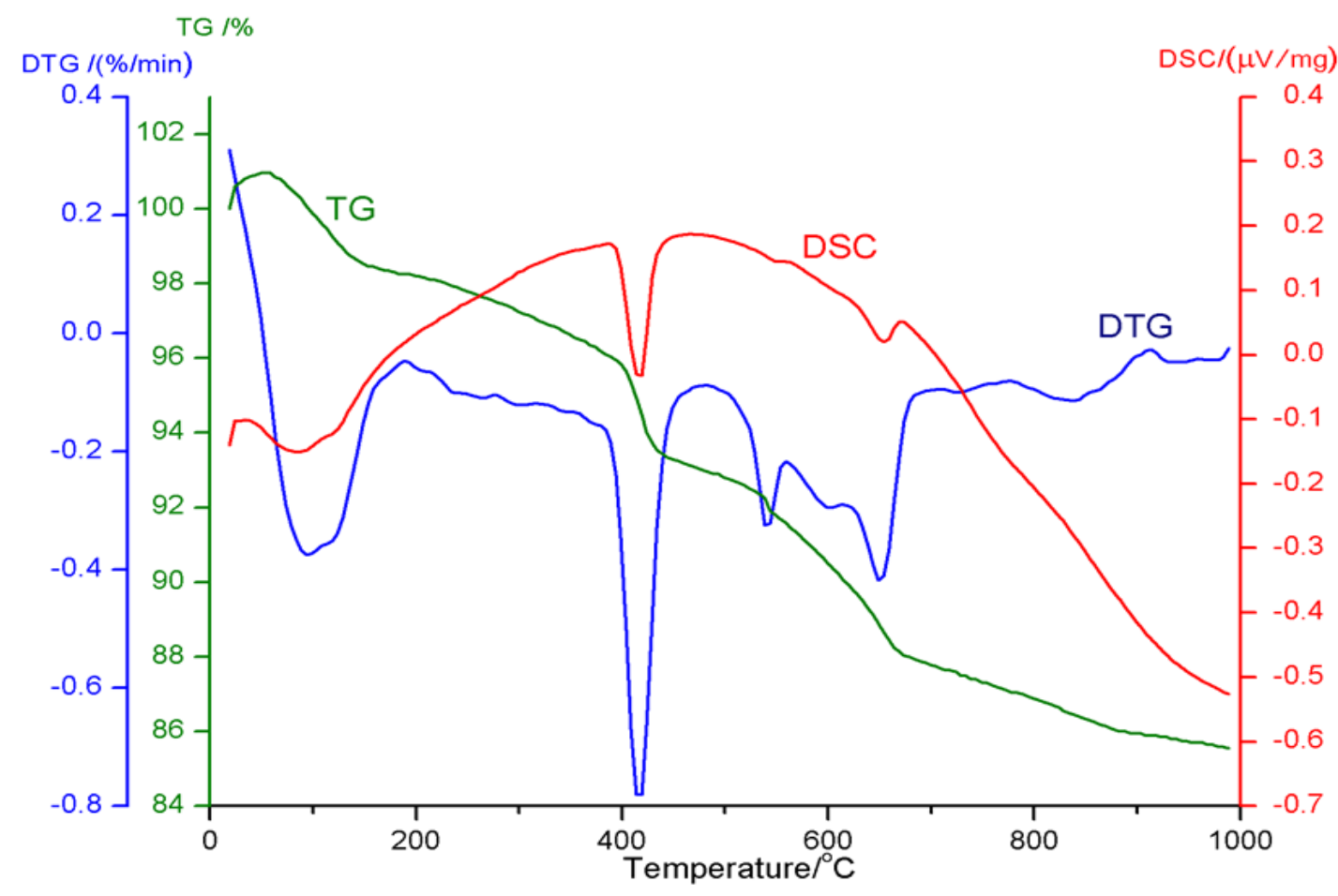

Fig. 4.1c: The TG, DSC and DTG thermograms of the hardened neat OPC after 28 days. 


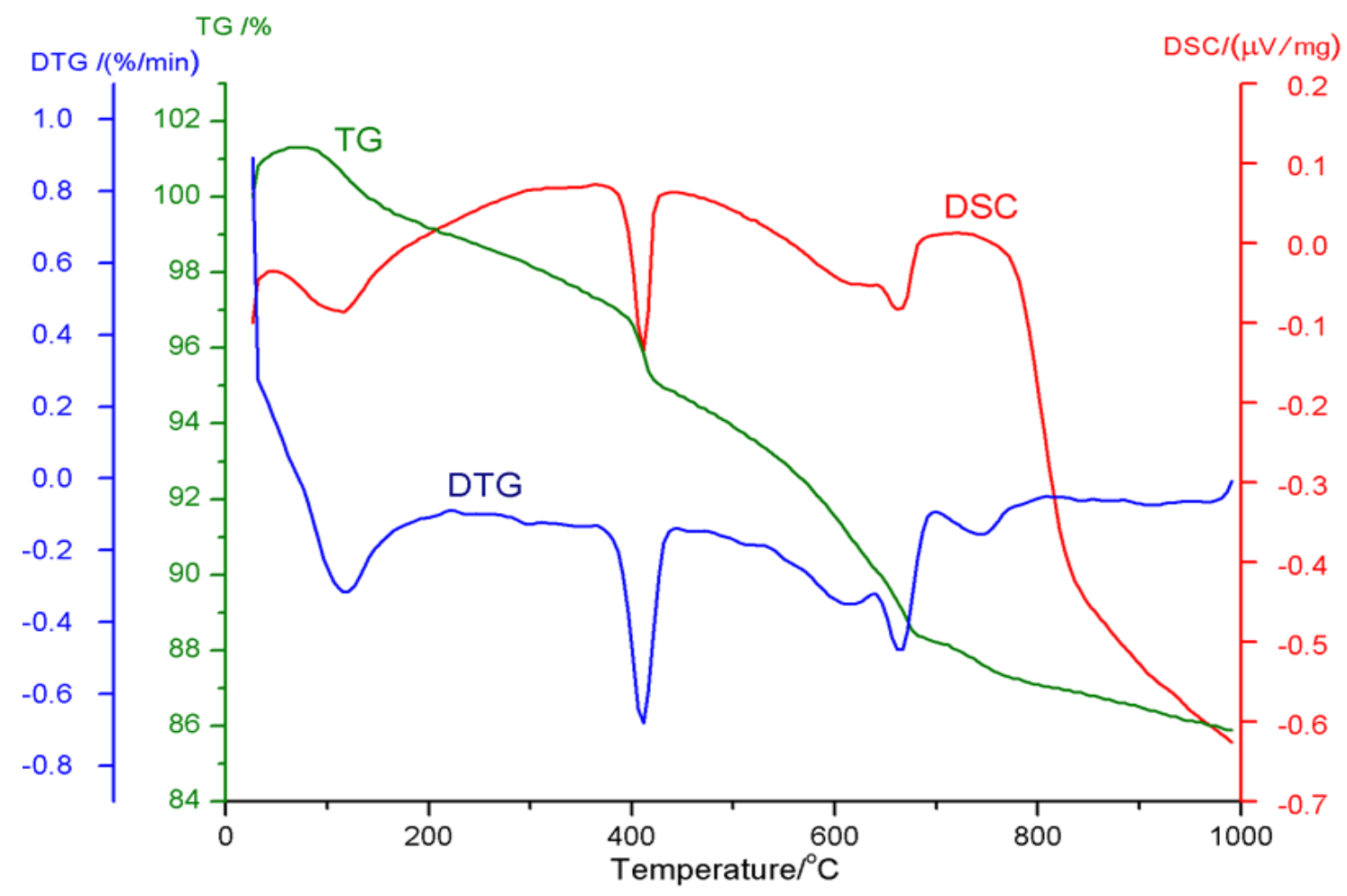

Fig. 4.2a: The TG, DSC and DTG thermograms of the hardened OPC-MK paste made of mix MK10 after 1 day.

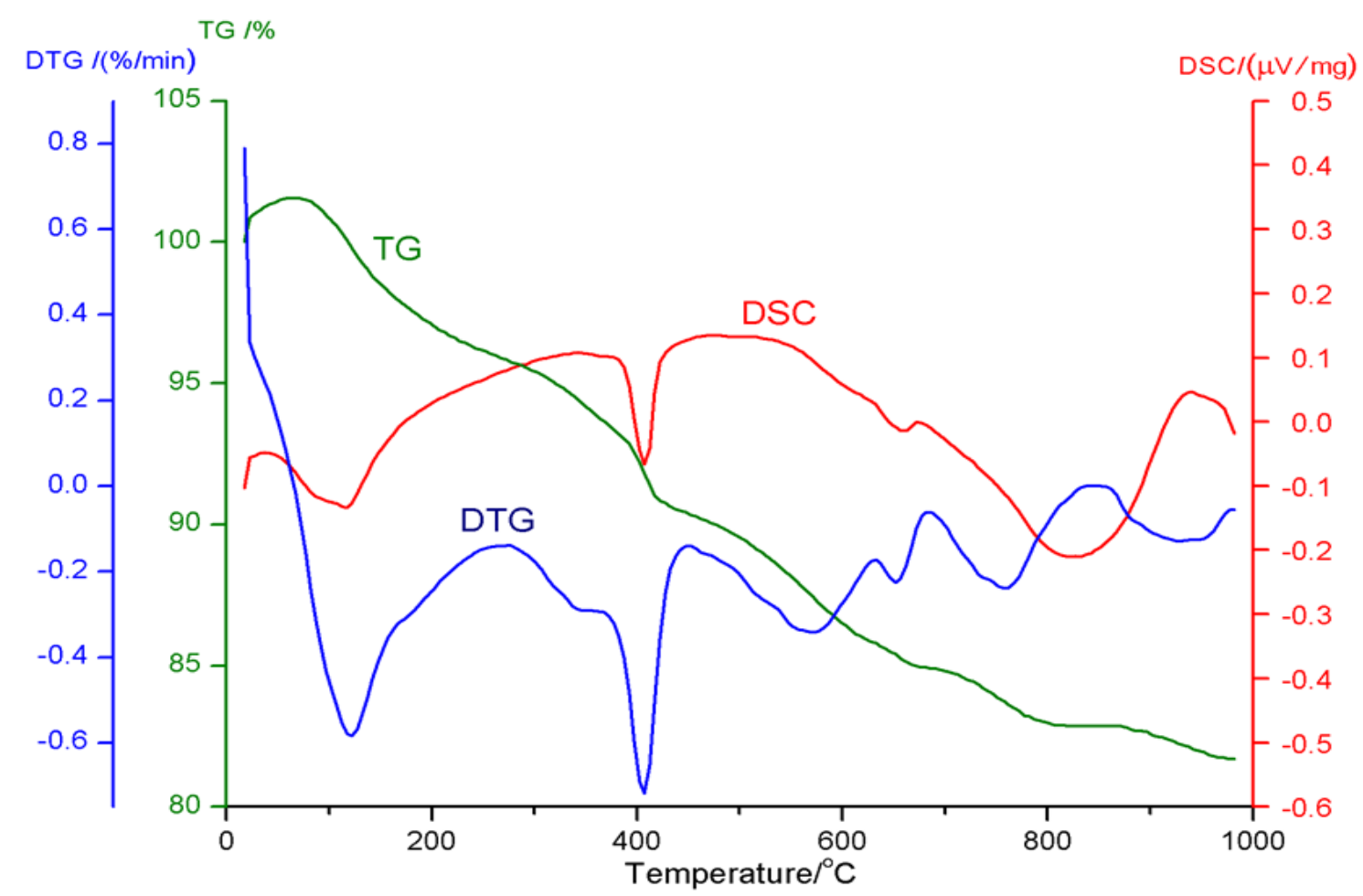

Fig. 4.2b: The TG, DSC and DTG thermograms of the hardened OPC-MK paste made of mix MK10 after 14 days. 


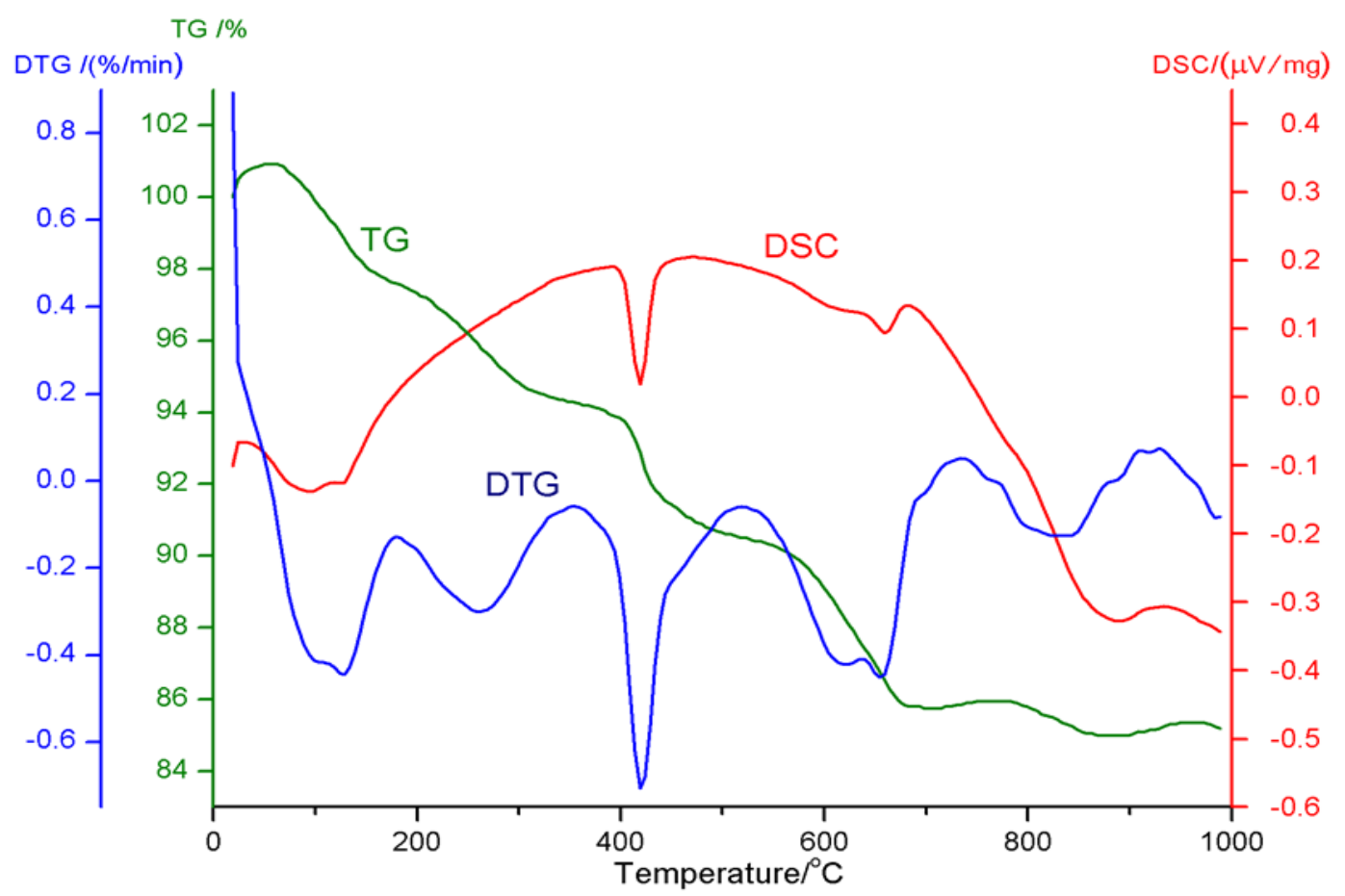

Fig. 4.2c: The TG, DSC and DTG thermograms of the hardened OPC-MK paste made of mix MK10 after 28 days.

\subsection{X-ray Diffraction Analysis}

X-ray diffractograms for the hardened cement pastes of neat OPC and OPC containing $10 \% \mathrm{MK}$ (MK0 and MK10) after 28 days of hydration are shown in figure 5 . The results indicate that the distinct phases identified for the neat OPC at 28 days of hydration. The peaks characterizing tricalcium aluminate $\left(\mathrm{C}_{3} \mathrm{~A}\right)$ were not detected as expected due to the fast rate of hydration and its reactivity with gypsum with the formation of ettringite $\left(\mathrm{C}_{3} \mathrm{~A} .3 \mathrm{CaSO}_{4} .32 \mathrm{H}_{2} \mathrm{O}\right)$ which is transformed to the mono-sulphate hydrate $\left(\mathrm{C}_{3} \mathrm{~A} . \mathrm{CaSO}_{4} .12 \mathrm{H}_{2} \mathrm{O}\right)$ during the early stages of hydration and overlapped with the peaks of unhydrated silicate phases and hydrated calcium silicates. The calcium hydroxide phase formed as a result of hydration of anhydrous calcium silicates in OPC clinker, could be distinguished, as well as the calcium silicate hydrates, $\mathrm{CSH}$ (I) and (II), as the main hydration products, figure 5 .

The main hydration products of hardened OPC paste blended with 10\% MK (mix MK10), are the nearly amorphous and microcrystalline calcium silicate hydrates (CSH), calcium hydroxide $(\mathrm{CH})$ and calcium aluminosilicate hydrates (CASH).

In conclusion, the intensity of $\mathrm{CH}$ peaks of blended cement paste containing $10 \% \mathrm{MK}$ (MK10) is lower than in case of neat OPC (MK0); this due to the consumption of $\mathrm{CH}$ after the reaction with MK (pozzolanic reaction). Meanwhile, the intensity of hydration products of calcium silicate hydrates $(\mathrm{CSH})$ and calcium aluminate silicate hydrates $(\mathrm{CASH})$ of mix MK10 is larger than in case of MK0. 


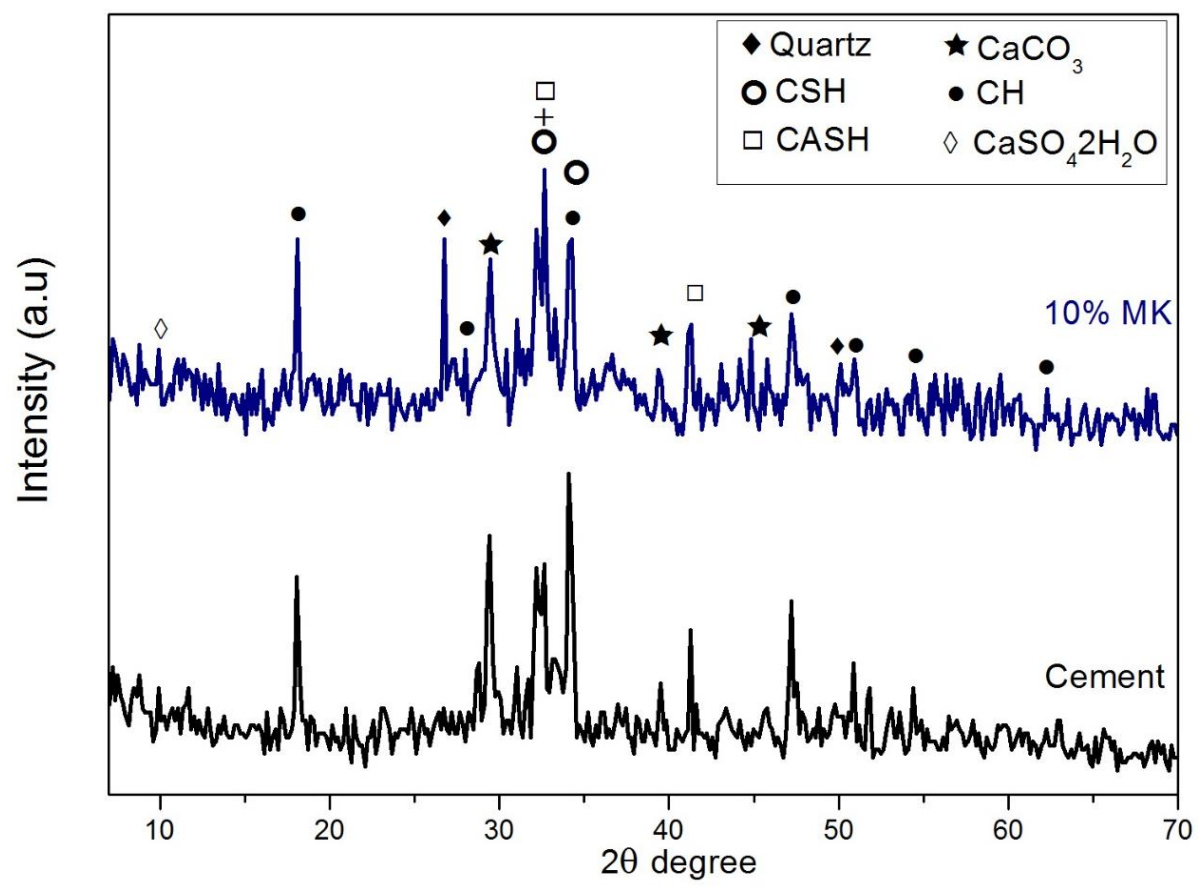

Fig. 5: XRD Patterns for the hardened cement pastes of neat OPC (MK0) and OPC containing 10\% MK (MK10) after 28 days of hydration.

\subsection{Scanning Electron Microscopy (SEM).}

The microstructure of the neat OPC paste (MK0) hydrated for 28 days is shown in figure 6. The formation of crumpled fibrous particles of tobermorite-like CSH phases was indicated as the dominant hydration products, figure 6 . The hexagonal calcium aluminate hydrates and hexagonal calcium hydroxide (portlandite) deposited in the originally water-filled spaces as well as unhydrated cement grains.
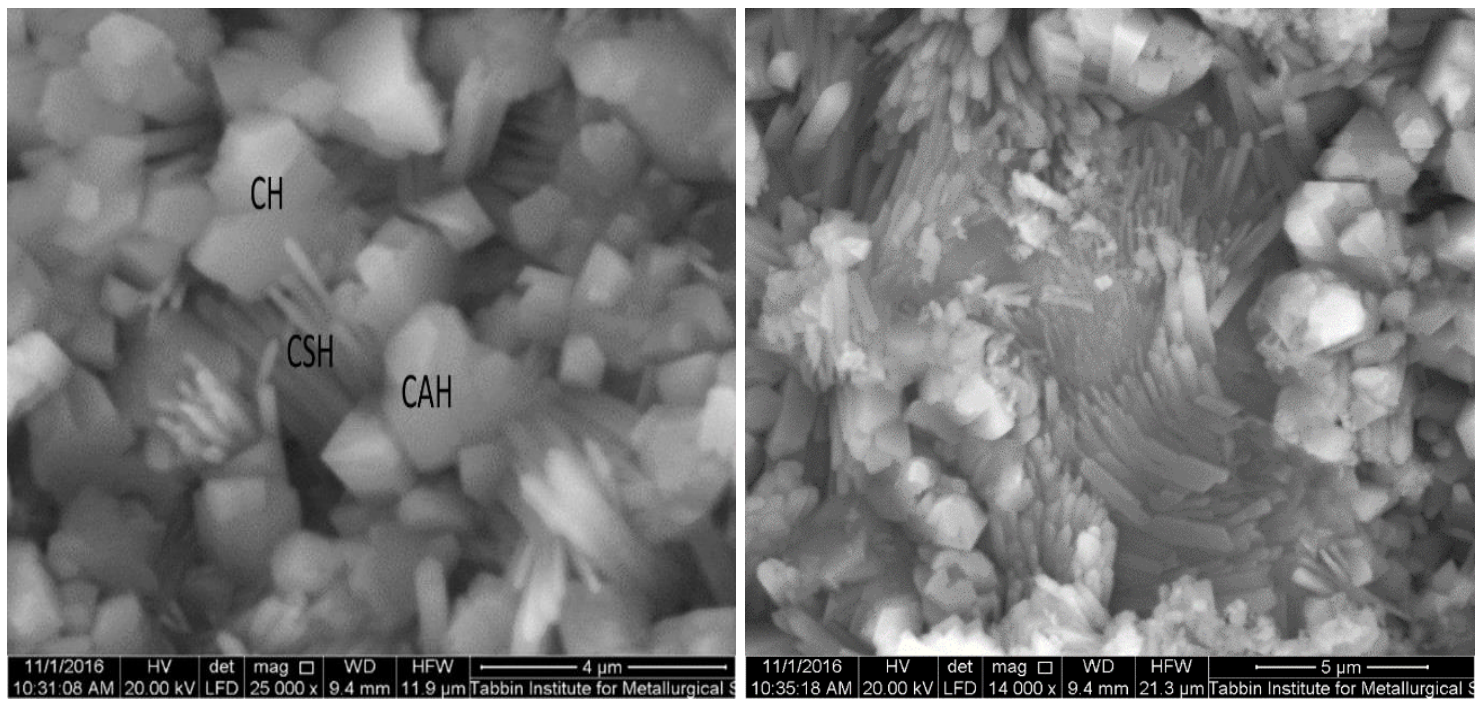

Fig. 6: SEM micrograph for the hardened neat OPC paste (MK0) after 28 days of hydration. 
The microstructure of the hardened OPC paste blended with $10 \% \mathrm{MK}$ (MK10) after 28 days of hydration are shown in figure 7. The SEM micrograph indicated the formation of crumpled fibrous particles with dense structure of tobermorite-like CSH phases as the dominant hydration products among the other hydrated phases deposited in the originally water-filled spaces in addition to the presence of unhydrated parts of cement and metakaolin grains. The crystals of calcium hydroxide $(\mathrm{CH})$ and porosity appeared in paste made of OPC without metakaolin addition (MK0) are relatively disappeared in this paste as a result of pozzolanic reaction with addition of $10 \% \mathrm{MK}$.
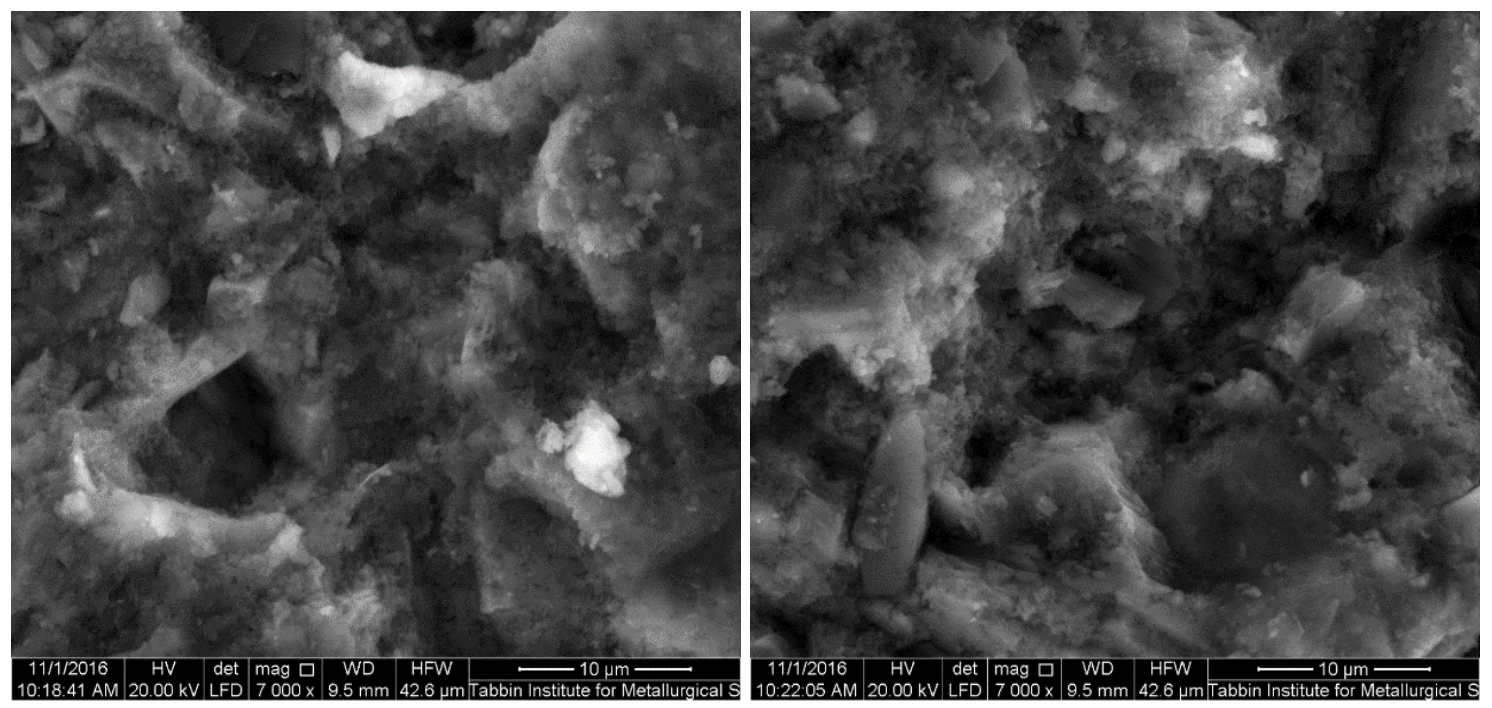

Fig. 7: SEM micrograph for the hardened OPC paste containing 10\% MK (MK10) after 28 days of hydration.

\section{Conclusions}

Based on the results in this investigation, the following could be concluded:

- The hardened blended cement pastes made of 90\% OPC $+10 \%$ MK possesses the highest strength values at all hydration ages as compared to other pastes containing 0,5 and $15 \% \mathrm{MK}$.

- The free lime contents obtained for all hardened blended pastes of OPC- MK are lower than those of the neat OPC paste.

- DSC thermograms and XRD diffractograms obtained for the hardened blended cement pastes and neat cement indicate the formation of nearly calcium silicate hydrates (mainly as CSH. I \& II), calcium sulphoaluminate hydrates (ettringite and monosulphate hydrates), calcium aluminate hydrates, $\mathrm{CH}$ and $\mathrm{CaCO}_{3}$.

- Scanning electron microscopy micrographs indicate the formation of denser microstructure for the hardened OPC- MK pastes as compared to neat OPC pastes after 28 days of hydrations.

\section{REFERENCES}

[1] Alessandra, M.; Alberto, B.; Chiara, G.; Tiziano, B. and Francesca, T.: "Metakaolin and fly ash alkali-activated mortars compared with cementitious mortars at the same strength class". Cement and concrete research, 88, pp. 198-210, (2016). 
[2] Zhenguo, S.; Lothenbach, B.; Geiker, M. R.; Kaufman, J.; Leemann, A.; Ferreiro, S. and Skibsted, J.: "Experimental studies and thermodynamic modeling of the carbonation of Portland cement, metakaolin and limestone mortars". Cement and concrete research, 88, pp. 60-72, (2016).

[3] Rashad, A. M.: "Cementitious materials and agricultural wastes as natural fine aggregate replacement in conventional mortar and concrete". Journal of building engineering, 5, pp. 119-141, (2016).

[4] Shafiq, N.; Nuruddin, M. F.; Khan, S. U. and Ayub, T.: "Calcined kaolin as cement replacing material and its use in high strength concrete". Construction and building materials, 81, pp. 313-323, (2015).

[5] Chao, L.; Henghu, S. and Longtu, L.: "A review: The comparison between alkali activated slag $(\mathrm{Si}+\mathrm{Ca})$ and metakaolin $(\mathrm{Si}+\mathrm{Al})$ cements". Cement and concrete research, 40, pp. 1341-1349, (2010).

[6] Poona, C. S.; Lama, L.; Koua, S. C.; Wonga, Y. L. and Wong, R.: "Rate of pozzolanic reaction of metakaolin in high-performance cement pastes". Cement and concrete research, 31, pp. 1301-1306, (2001).

[7] Walker, R. and Pavia, S.: "Physical properties and reactivity of pozzolans, and their influence on the properties of lime-pozzolan pastes". Materials and structures, 44, pp. 1139-1150, (2011).

[8] Ming, L. Y.; Yong, H. C.; Al Bakri, M. M. and Hussin, K.: "Structure and properties of clay-based geopolymer cements: A review". Progress in materials science, 83, pp. 595-629, (2016).

[9] Hollanders, S.; Adriaens, R.; Skibsted, J.; Cizer, O. and Elsen, J.: "Pozzolanic reactivity of pure calcined clays". Applied clay science, 132-133, pp. 552-560, (2016).

[10] Tchakoute, H. K.; Rüscher, C. H.; Djobo, J. N. Y.; Kenne, B. B. D. and Njopwouo, D.: "Influence of gibbsite and quartz in kaolin on the properties of metakaolin-based geopolymer cements". Applied clay science, 107, pp. 188-194, (2015).

[11] El-Diadamony, H.; Amer, A. A.; Sokkary, T. and El-Hoseny, S.: "Hydration and characteristics of metakaolin pozzolanic cement pastes". HBRC Journal, (2016).

[12] Subas, A. and Emiroglu, M.: "Effect of metakaolin substitution on physical, mechanical and hydration process of white Portland cement". Construction and building materials, 95, pp. 257-268, (2015).

[13] Yuhuan, B.; Jiapei, D.; Shenglai, G.; Huajie, L. and Chenxing, H.: "Properties of oil well cement with high dosage of metakaolin". Construction and building materials, 112, pp. 39-48, (2016).

[14] Rashad, A. M.: "Metakaolin as cementitious material: history, scours, production and composition - a comprehensive overview". Construction and building materials, 41, pp. 303-318, (2013).

[15] Mahyuddin, B. R. and Alonge, O. R.: "Characterization of metakaolin and study on early age mechanical strength of hybrid cementitious composites". Construction and building materials, 121, pp. 599-611, (2016).

[16] Ioannis, P. S.; Efstratios, G. B. and Konstantinos, G. T.: "Rheology and mechanical characteristics of self-compacting concrete mixtures containing metakaolin". Construction and building materials, 64, pp. 121-129, (2014).

[17] Guang, J.; Zhidan, R. and Wei, S.: "Effects of metakaolin on mechanical properties, pore structure and hydration heat of mortars at $0.17 \mathrm{w} / \mathrm{b}$ ratio". Construction and building materials, 93, pp. 564-572, (2015). 
[18] Shoukry, H.; Kotkata, M. F.; Abo-EL-Enein, S. A.; Morsy, M. S. and Shebl, S. S.: "Enhanced physical, mechanical and microstructural properties of lightweight vermiculite cement composites modified with nano metakaolin". Construction and building materials, 112, pp. 276-283, (2016).

[19] Abo-El-Enein, S. A.; Amin, M. S.; El-Hosiny, F. I.; Hanafi, S.; ElSokkary, T. M. and Hazem, M. M.: "Pozzolanic and hydraulic activity of nano-metakaolin". HBRC Journal, 10, pp. 64-72, (2014).

[20] El-Gamal, S. M. A.; Amin, M. S. and Ramadan, M.: "Hydration characteristics and compressive strength of hardened cement pastes containing nano-metakaolin". HBRC Journal, (2015).

[21] Egyptian specification: "The standard methods for the chemical analysis", (2010).

[22] Abo-El-Enein, S. A.; Abbas, R. and El-Sayed, E.: "Properties and durability of metakaolin blended cements". Mater. de constr., 60, pp. 21-35, (2010).

[23] Mansour, M. S.; Kadri, E.; Kenai, S.; Ghrici, M. and Bennaceur, R.: "Influence of calcined kaolin on mortar properties". Constr. and build. mater., 25, pp. 2275-2282, (2011).

[24] Pera, J.; Rols, S.; Chabannet, M. and Ambroise, J.: "Influence of the cement type on the resistance of concrete to an agricultural environment". In Cohen, M.; Mindess, S. and Skalny, J. editors. Materials science of concrete, the Sidney diamond symposium, Amer. concr. soc., pp. 419-430, (1998).

[25] Mlinarik, L. and Katalin, K.: "Impact of metakaolin - a new supplementary material on the hydration mechanism of cements". Acta technical napocensis - civil engineering and architecture, 56, pp. 100-110, (2013).

[26] Frias, M. and Cabrera, J.: "The influence of MK on the reaction kinetics in MK/ lime and MK- blended cement systems at $20^{\circ} \mathrm{C} "$. Cem. conc. res. 31, pp. 519-527, (2001). 